\title{
Effect of casting direction on bond of reinforcement in High Performance Self-Compacting Concrete (HPSCC)
}

\author{
Piotr Dybel ${ }^{1, *}$ \\ ${ }^{1}$ AGH University of Science and Technology, Faculty of Mining and Geoengineering, Department of Geomechanics, Civil \\ Engineering and Geotechnics, al. Mickiewicza 30, 30-059 Cracow, Poland
}

\begin{abstract}
This paper presents the results of an investigation into the steel-to-concrete bond in highperformance self-compacting concrete (HPSCC) based on direct pull-out tests. Specifically, the effect of the casting direction on bond properties is examined. Two variants of concrete mixture casting were considered in this work: from the top and from the bottom of a mould with a single casting point at one edge. Horizontal specimens with transverse rebars distributed over their heights $(480 \mathrm{~mm})$ and lengths $(1600 \mathrm{~mm})$ were cast. The experimental program has shown that the direction of concreting plays an important role in the formation of the bond condition. In the case of casting a mixture from the bottom of a mould, in the lower part of a specimen there is no significant change of the bond stress. However, there is a strong improvement in the upper part. The phenomenon observed eliminates the top-bar effect. What is more, for the rebars situated in the upper part of a specimen, improvements in bond characteristics, such as the bond stiffness, bond strength and the effect of the rebar distance from the casting point are all observed in the case of casting a mixture from the bottom of a mould.
\end{abstract}

\section{Introduction}

The most universal and currently most widely used construction material is concrete. Although the first applications of concrete date back to $\mathrm{BCE}$, the development of its production technology has been observed to this day. Continuous modifications make it necessary to assess afresh the mechanical properties of this material. This is also true of the bond between new generation concretes and reinforcement bars.

New generation concretes include, among others, high performance concrete (HPC) and high performance self-compacting concrete (HPSCC), which was created based on the concept of self-compacting concrete (SCC) and HPC. HPSCC is thus characterized by its ability to fill a form completely accompanied by venting and selfleveling with no need for mechanical compaction and by a high compression strength as well as high durability. Obtaining such properties requires a specific composition and proportion of ingredients. The HPSCC mixture, as compared to ordinary concrete, has a higher content of Portland cement, superplasticizers and reactive mineral additives, most frequently in the form of silica fume [9-11].

The HPSCC mixture exhibits high resistance to free water draining and also decreased segregation and sedimentation in comparison to the ordinary concrete mixture. High quality of the new generation concrete mixture causes that the main factors affecting the bond between the concrete and reinforcement bars are significantly reduced. The rheological properties of the HPSCC mixture described here allow a few variants of casting into moulds. Casting may be performed either from the top or from the bottom of the a mould. It is also possible to fill a whole mould from just a single mixture casting point.

In the literature, one can find merely a few works dedicated to the problem analysed here [15-19]. Those works focused only on evaluating the influence of the changes of the bond between reinforcement bars and concrete depending on the distance to the mixture casting point. Previous work has shown that issues arose especially for lower slump-flow values and for greater distances from the casting point. It should be noted that a descending slope of the final surface in the case of SCC has been observed for larger distances from the casting point, up to $2.20 \mathrm{~m}$ [18], which resulted in a reduction of the steel cover. In the case of distances from the casting point of up to $1.40 \mathrm{~m} \mathrm{[17],} \mathrm{it} \mathrm{was} \mathrm{proven} \mathrm{that} \mathrm{bond}$ strengths are higher at the middle bars compared to the bars at both extremities. This could be due to the uniform mixture in the middle parts of the horizontal specimens. The average drop of normalised bond strength of the steel bars across the length of the specimens was approximately $11 \%$. But there are studies available in which no bond loss is evident for distances from the casting point of up to at least $1.60 \mathrm{~m}[15,16]$. For shorter distances from the casting point, up to $0.90 \mathrm{~m}$ [19], no evident bond loss was observed.

\footnotetext{
* Corresponding author: dybel@agh.edu.pl
} 
However, no research has been conducted to assess the top-bar effect in horizontal specimens with a single casting point. What is more, the hitherto studies have not analysed the influence of the casting direction in the case of a self-compacting mixture - from the top and bottom of a mould - on the rebar-concrete bond. Furthermore, norm guidelines in this field have been missing.

\section{Scope of research}

The author of this study has attempted to assess the change in the concrete bond to steel rebars along the lengths of monolithic elements made of HPSCC. Specifically, the top-bar effect on the bond variation across horizontal specimens was examined. Two variants of concrete mixture casting were considered in this research: from the top and from the bottom of a form with a single casting point at a specimen's edge.

In total, 48 cubic specimens were cast and tested at the age of 28 days by performing pull-out tests according to EN 10080:2005 [23]. Additionally, another 20 cubic specimens were tested in order to determine the corresponding 28-day compressive strength.

\section{Experimental program}

\subsection{Materials and concrete mixtures}

In this experimental program, a high performance selfcompacting concrete mixture was used. The composition of the mixture was developed based on the authors' own experiences and work guidelines [9]. The composition of the concrete mixture is given in table 1 . Table 2 shows the rheological properties of the mixture and the average values of the compressive strength obtained for the solidified concrete.

The bond tests were performed for ribbed reinforcing bars (B500SP). A bar diameter of $16 \mathrm{~mm}$, representative of the so-called mean diameters $(10-20 \mathrm{~mm})$, was used [23].
The mean values of the mechanical properties of the reinforcing bars are shown in table 3 .

Table 1. Composition by mass of proposed mix, $\left[\mathrm{kg} / \mathrm{m}^{3}\right]$.

\begin{tabular}{|c|c|}
\hline Cement CEM I 42.5R & 500 \\
\hline Water & 176 \\
\hline Sand 0/2 mm & 790 \\
\hline Basalt aggregate 2/8 mm & 940 \\
\hline Silica fume & 50 \\
\hline Superplasticizer & 6.27 \\
\hline Water/binder ratio & 0.32 \\
\hline Silica fume level & $10 \%$ \\
\hline
\end{tabular}

Table 2. Details of concrete mixes.

\begin{tabular}{|c|c|c|c|c|c|c|c|c|}
\hline $\begin{array}{c}\text { Slump } \\
\text { flow }\end{array}$ & $\begin{array}{c}\text { flump } \\
\text { flow } \\
\text { [cm] }\end{array}$ & $\begin{array}{c}\text { clump } \\
\text { class }\end{array}$ & $\begin{array}{c}\text { fiscosity } \\
\text { time } \\
\text { class }\end{array}$ & $\begin{array}{c}\text { L- } \\
\text { box } \\
\text { ratio }\end{array}$ & $\begin{array}{c}\text { L- } \\
\text { box }\end{array}$ & $\begin{array}{c}\text { Fresh } \\
\text { visual } \\
\text { stability } \\
\text { index }\end{array}$ & $\begin{array}{c}\text { Compressive } \\
\text { strength }\end{array}$ \\
\hline 71 & SF2 & 2.5 & VS2 & 0.89 & PL2 & 0 & 91.7 & 5.4 \\
\hline
\end{tabular}

Table 3. Mean values of mechanical parameters of reinforcing bars.

\begin{tabular}{|c|c|c|c|c|}
\hline $\begin{array}{c}\text { Diameter } \\
{[\mathbf{m m}]}\end{array}$ & $\begin{array}{c}\text { Modulus } \\
\text { of } \\
\text { elasticity } \\
{[\mathbf{G P a}]}\end{array}$ & $\begin{array}{c}\text { Yield } \\
\text { point, } \\
\text { upper } \\
\boldsymbol{R}_{\boldsymbol{e H}} \\
{[\mathbf{M P a}]}\end{array}$ & $\begin{array}{c}\text { Tensile } \\
\text { strength } \\
\boldsymbol{R}_{\boldsymbol{m}} \\
{[\mathbf{M P a}]}\end{array}$ & $\begin{array}{c}\text { Strain at } \\
\text { maximal } \\
\text { force } \\
\boldsymbol{A}_{\boldsymbol{g t}} \\
{[\%]}\end{array}$ \\
\hline 16 & 202.1 & 558.1 & 633.2 & 13.54 \\
\hline
\end{tabular}

\subsection{Description of specimens}

The experiments were conducted on specimens $(160 \mathrm{x}$ $1600 \times 480 \mathrm{~mm}$ ) with transverse reinforcement bars embedded over their heights and across their lengths, respectively. The dimensions of the specimens were multiples of the basic module recommended by RILEM [24] and EN 10080:2005 [23] (10 $\phi \times 10 \phi \times 10 \phi)$. A schematic view of a test element is shown in figure 1 .
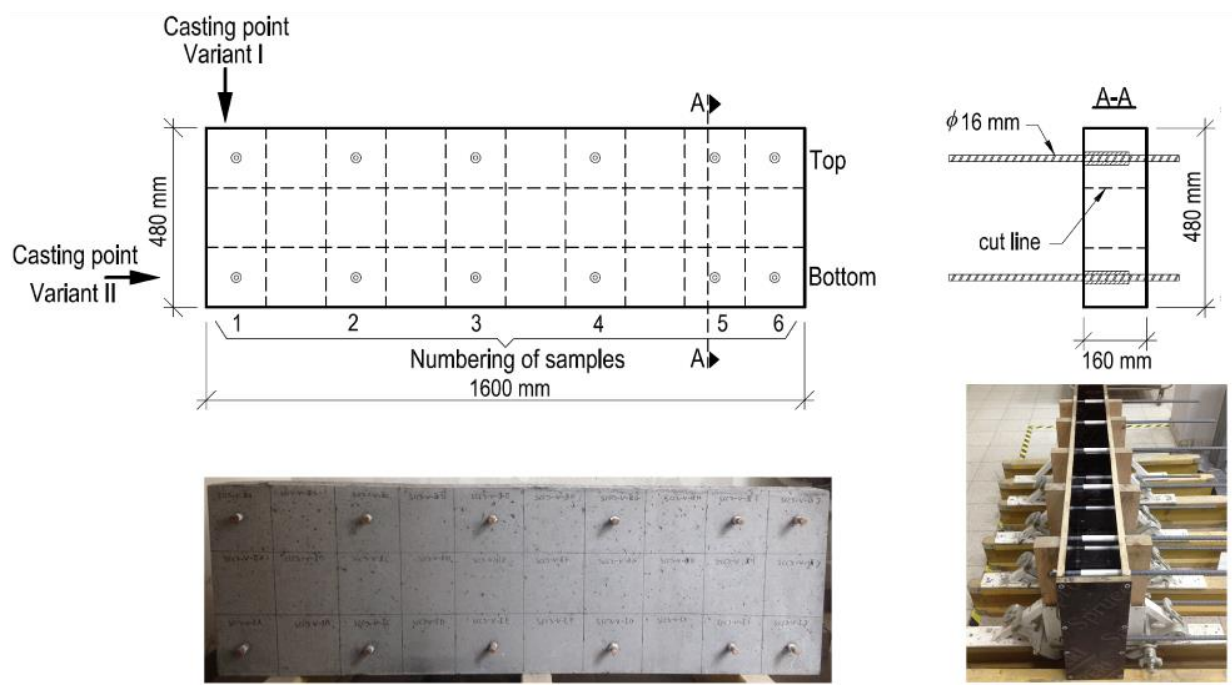

Fig. 1. Schematic view of test element. 
Two variants of concrete mixture casting were considered in this work:

- variant I - casting from the top of a mould with a single casting point at a specimen's edge,

- variant II - casting from the bottom of a mould with a single casting point at a specimen's edge.

Concreting from the bottom was executed by casting the concrete mixture to a specially prepared piping routed above the upper level of the mould. The concrete mixture filled the mould from the bottom under its own weight following the concept of communicating vessels. Two series of tests were carried out for each variant of concrete mixture casting.

The specimens produced were next left for 3 days in a formwork. After formwork stripping the samples were kept in the laboratory in unchanged positions. Before tests, the samples were protected against vibrations and constantly cared for through water sprinkling. After 21 days, the specimens were cut into elementary parts.

\subsection{Test methods}

The concrete bond tests were carried out on the bars using the RILEM [24] and EN 10080:2005 [23] method based on the pull-out test. This is a fundamental method for an assessment of the reinforcing bars - concrete interaction, which depends on the concrete's properties and the type of the reinforcing bars. The idea is to apply a tensile load to a bar anchored in a concrete block. The values measured correspond to the force applied to the bar and the relative displacement between the steel and the concrete.

The test model adopted allowed for the assumption that the strain changes in the steel along the bar's axis were linear. With this assumption in place, the value of a bond stress is constant and can be calculated from the following formula:

$$
\tau=\frac{F}{\pi \phi l}
$$

where:

$$
\begin{array}{lll}
F & - & \text { the force applied, } \\
\phi & - & \text { the reinforcing bar diameter, } \\
l & - & \text { the bond section length. }
\end{array}
$$

The bond section length in this study was $3 \phi$. The force applied to a rebar was exerted gradually up to the bond failure. Measurements of the displacements of the unloaded end of the rebar with respect to the concrete were made using two linear variable displacement transducers (LVDT). A computer data collection system was used.

In this article, two different representative values of the bond stress are adopted. These values are often used in the literature regarding the problem under consideration. The first value is the ultimate bond stress corresponding to a destruction of the rebar-concrete bond - $\tau_{\max }$. This criterion is most frequently used in the literature as a result of its unambiguous definition $[5,8$, 12-14]. The second representative value commonly applied in the literature $[4,16,20]$ is the critical bond stress corresponding to a slip of a rebar with respect to concrete of $0.25 \mathrm{~mm}-\tau_{0.25}$.

In order to compare the results from this work with other literature results, a commonly used normalization was introduced in which the bond stress is divided by the square root of the compressive strength $\tau / \mathrm{f}_{\mathrm{c}}{ }^{0.5}[12,15$, $22]$.

\section{Results and discussion}

The relation courses of the bond stress-slip $\left(\tau / f_{c}^{0.5}-s\right)$ curves obtained in this study are presented in figure 2 . For each of the variants of the study model analysed, the $\tau / f_{c}^{0.5}-s$ relation was formed out of the mean values for the results of the tests for two identical elements. Table 4 shows the values of the critical and ultimate representative bond stresses obtained. For all the samples, the observed type of the rebar-concrete connection destruction was associated with pulling the rebar out from the concrete.
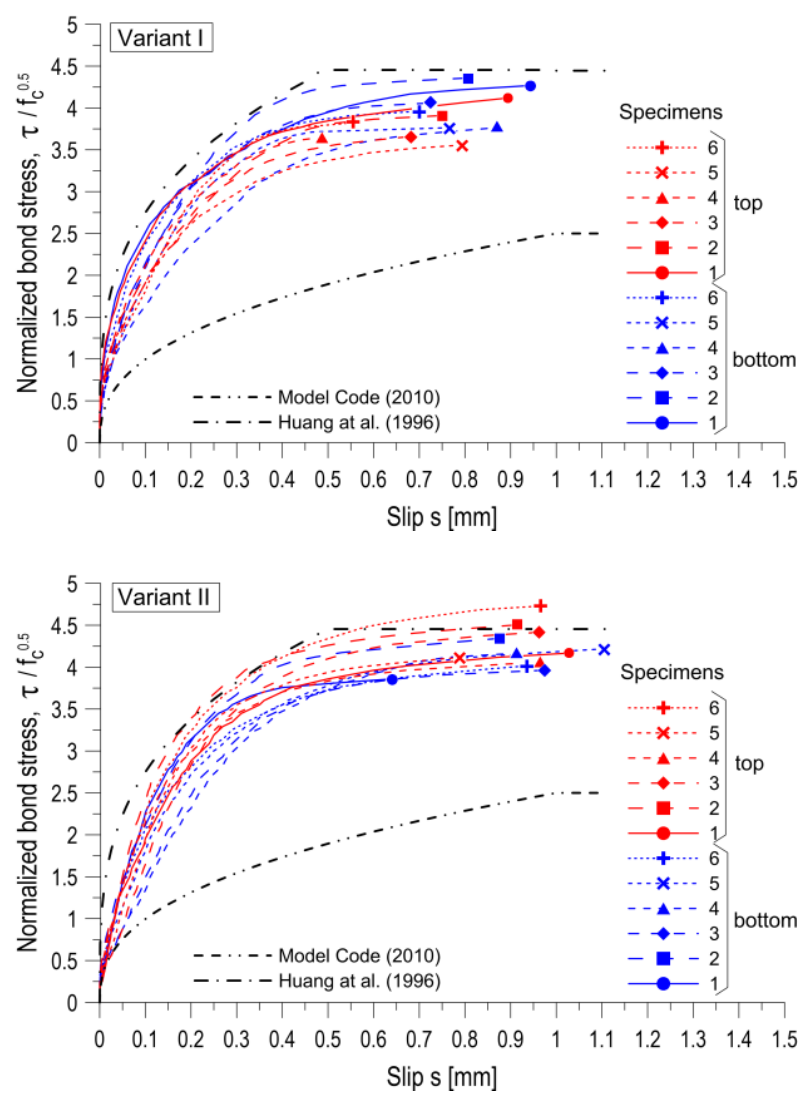

Fig. 2. Normalized representative bond stresses vs. slip.

\subsection{Bond-slip curves}

In fig. 2, the normalized bond-slip curves are presented for all the pull-out tests conducted on all bars. Based on a comparison of the $\tau / f_{c m}{ }^{0.5}-s$ curves, it can be noted that the shape and slope depend on the position of a rebar in a concrete element and the mix casting direction. The courses of the bond stress-slip curves are similar to the bond functions proposed for high-strength concrete [21] (fig. 2). A small difference between the deformability of 
the HPSCC matrix and the aggregate reduces the concentration of stress in the rebar-concrete contact layer and increases the homogeneity of the stress distribution. Thanks to this, the formation of micro-scratches and their propagation are significantly reduced at lower load levels.

The tests have shown that for the bars positioned in the lower part of a specimen the direction of concreting did not have an important effect on their bond stiffness (a change in the bond strain increment relative to the bar displacement in concrete). In turn, for the bars situated in the upper part of a member, a significant improvement of the bond stiffness was observed when casting was performed from the bottom of a mould. It should be stated that for this concreting variant higher representative bond stress values $\left(\tau_{0.25}\right.$ and $\left.\tau_{\max }\right)$ were obtained as compared to traditional casting from the top of a form.

Table 4. Representative bond stresses for the rebars of the element.

\begin{tabular}{|c|c|c|c|c|c|c|c|c|c|}
\hline \multirow{3}{*}{\multicolumn{2}{|c|}{ Rebar }} & \multicolumn{4}{|c|}{$\tau_{\max } / f_{c}^{0.5}$} & \multicolumn{4}{|c|}{$\tau_{0.25} / f_{c}^{0.5}$} \\
\hline & & \multirow{2}{*}{$\begin{array}{c}\text { Varian } \\
\text { I }\end{array}$} & \multirow{2}{*}{ 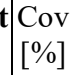 } & \multirow{2}{*}{$\begin{array}{c}\text { Variant } \\
\text { II }\end{array}$} & \multirow{2}{*}{$\begin{array}{l}\mathrm{Cov} \\
{[\%]}\end{array}$} & \multirow{2}{*}{$\begin{array}{c}\text { Variant } \\
\text { I }\end{array}$} & \multirow{2}{*}{$\begin{array}{l}\mathrm{Cov} \\
{[\%]}\end{array}$} & \multirow{2}{*}{$\begin{array}{c}\text { Varian } \\
\text { II }\end{array}$} & \multirow{2}{*}{$\begin{array}{l}\mathrm{Cov} \\
{[\%]}\end{array}$} \\
\hline & & & & & & & & & \\
\hline \multirow{6}{*}{$\stackrel{8}{\circ}$} & 1 & 4.12 & 8.5 & 4.17 & 5.4 & 3.29 & 9.5 & 3.19 & 6.4 \\
\hline & 2 & 3.92 & 8.2 & 4.50 & 8.1 & 2.96 & 10.5 & 3.68 & 9.1 \\
\hline & 3 & 3.67 & 11.1 & 4.43 & 11.1 & 2.98 & 9.3 & 3.19 & 6.5 \\
\hline & 4 & 3.67 & 11.3 & 3.96 & 7.7 & 3.11 & 10.2 & 3.22 & 7.7 \\
\hline & 5 & 3.57 & 9.4 & 4.12 & 8.0 & 2.81 & 9.1 & 3.35 & 8.1 \\
\hline & 6 & 3.82 & 9.7 & 4.73 & 10.7 & 3.22 & 10.7 & 3.55 & 9.0 \\
\hline \multirow{6}{*}{$\begin{array}{l}\stackrel{\Xi}{0} \\
\stackrel{\Xi}{0} \\
0\end{array}$} & 1 & 4.27 & 7.5 & 3.86 & 5.5 & 3.27 & 8.1 & 3.40 & 9.0 \\
\hline & 2 & 4.37 & 7.2 & 4.34 & 9.5 & 3.47 & 11.5 & 3.45 & 8.2 \\
\hline & 3 & 4.07 & 6.4 & 3.96 & 9.2 & 3.28 & 9.5 & 2.83 & 5.8 \\
\hline & 4 & 3.77 & 10.1 & 4.27 & 6.7 & 2.61 & 11.9 & 2.73 & 5.3 \\
\hline & 5 & 3.77 & 8.3 & 4.22 & 10.6 & 3.11 & 9.8 & 3.00 & 9.6 \\
\hline & 6 & 3.97 & 9.5 & 3.87 & 8.1 & 3.33 & 13.6 & 3.09 & 8.1 \\
\hline
\end{tabular}

\subsection{Effect of distance from casting point}

The effect of the rebar distance from the casting point on the bond was examined by comparing the normalized critical and ultimate bond stresses between the successive reinforcement bars across the lengths of the horizontal specimens. The results are presented in table 4 and figures 3 and 4.

The research conducted has shown that casting from the bottom of a mould led to an increase of the representative bond stress values for the rebars situated in the upper part of an element. However, for the rebars in the lower part, a change of the casting direction did not substantially affect the bond stress values obtained. Additionally, an increase of the ultimate and critical bond stress was observed for both the lower and the upper rebars situated at the edge of an element opposite to the casting point. Based on this observation, one may conclude that there is a positive effect of extra concrete mixing as the concrete bounces off the formwork.

This work has demonstrated the presence of the effect of the rebar distance from the casting point. The effect analysed depends on the direction of concrete mixture casting. In the case of casting concrete from the top, there is a reduction of the ultimate bond stress with the distance from the concrete casting point.

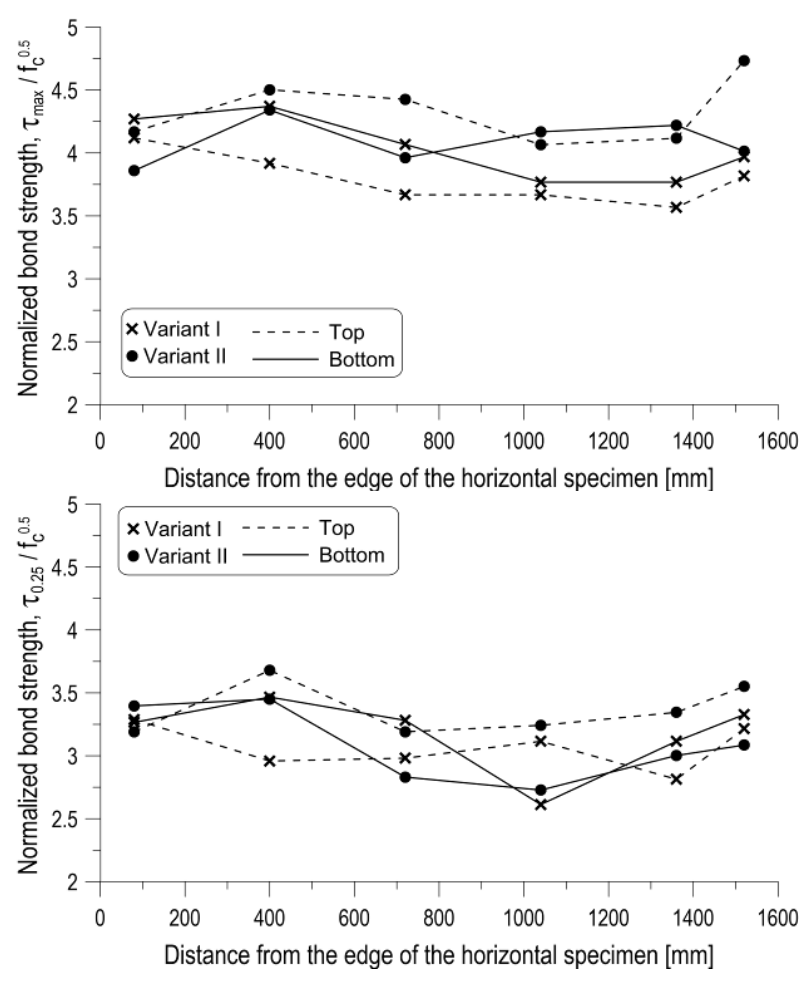

Fig. 3. Normalized bond strength as a function of rebar position.
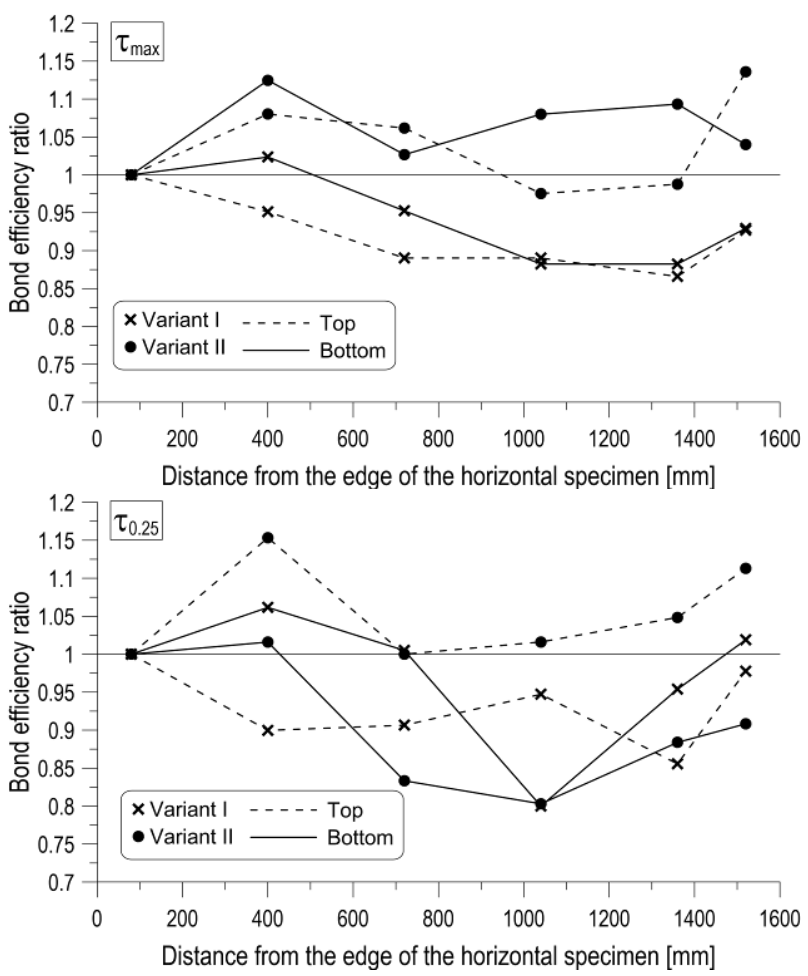

Fig. 4. Bond efficiency ratio as a function of rebar position. 
The maximum value of the bond reduction obtained between the successive rebars across the length of a specimen was $12.5 \%$ for both the upper and lower rebars. The results of the research on SCC presented in the literature give a similar bond reduction value, which in a 1.4-metre-long element was $11 \%$ [17]. In the case of casting in the bottom-to-top direction, the opposite tendency was observed. There were either no changes or an increase of the critical bond stress along a test member for both the upper and lower bars. The maximum value of the bond increase between the successive rebars across the length of a specimen was $12 \%$ and $14 \%$ for the lower and upper rebars, respectively.

Similar tendencies can be seen when analysing the effect of the distance from the casting point with respect to the critical bond stress. It should be stated that for $\tau_{0.25}$ there is greater result dispersion associated with the fact that the effect of bond stiffness changes is taken into account.

\subsection{Effect of rebar position over height}

In the experiment performed, the study elements were designed to allow an analysis of the rebar position (the reinforcement distance from the lower element surface) depending on the distance from the casting point. The corresponding test results are presented in table 4 and in figure 5 .

An inspection of the condition of the concrete surface around the reinforcement carried out after the pull-out tests revealed the presence of a 'poor' bond zone. The weakening of the concrete cover registered was present especially under the surface of the rebars situated in the top layer in the top-down casting scenario. The phenomena observed included local weakening of the concrete as a result of confinement of air cells under the surface of the reinforcement, a formation of voids as free water remnants and settlement of a fresh concrete mixture. In the case of casting from the bottom of a form, the aforementioned phenomena either did not occur or occurred on a much smaller scale.

The change of the ultimate bond stress values between the top and bottom specimens $\left(\tau_{\text {top }} / \tau_{\text {bottom }}\right)$ was clearly dependent on the direction of concrete mix casting. In the case of casting from the top of a mould, the bond condition became worse with an increasing distance from the bottom of the mould. Nevertheless, the modified micro-structure and different mechanical and rheological properties of HPSCC make the zone of the so-called 'poor' bond condition reduced. Moreover, its influence on the bond is much smaller than in ordinary concretes [6, 7]. For the direction of casting under consideration, the $\tau_{\text {top }} / \tau_{\text {bottom }}$ ratio was in the range from 0.9 to 0.97 . Meanwhile, casting from the bottom of a mould led to a virtually complete elimination of the 'poor' bond condition zone. Additionally, a tendency was observed in which higher bond stress was achieved in the upper rebars than in the lower rebars. The $\tau_{\text {top }} / \tau_{\text {bottom }}$ ratio was in the range $0.98-1.18$.
From the research that has been carried out, one can conclude that the top-bottom bond stress ratio does not change significantly with the distance from the concrete mix casting point. This is related to a similar change of the bond along the element in both its upper and lower part.
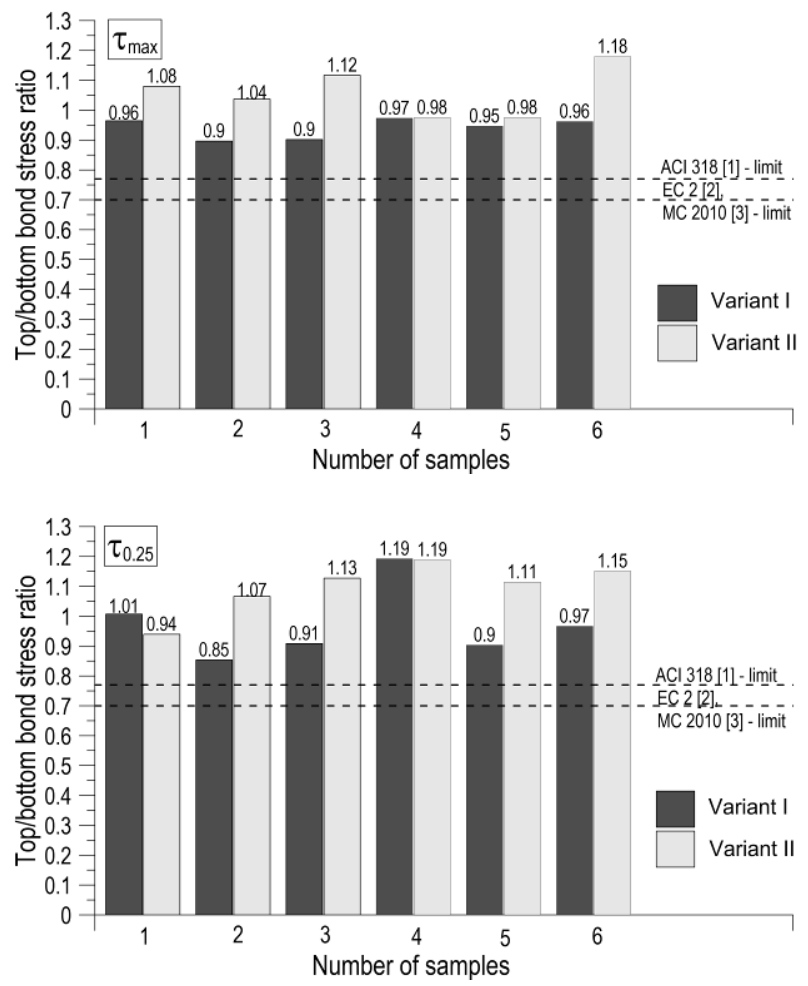

Fig. 5. Top-to-bottom stress ratio.

The behaviour of the $\tau_{\text {top }} / \tau_{\text {bottom }}$ ratio observed in the case of the critical bond stress was alike. In the variant of casting from the top of a mould, the $\tau_{\text {top }} / \tau_{\text {bottom }}$ ratio was in the range from 0.85 to 1.19 , whereas in the bottom-totop scenario the $\tau_{\text {top }} / \tau_{\text {bottom }}$ ratio was in the range 0.94 1.19 .

The results of the authors' own experiments presented here show that in the case of elements made of high-quality concretes containing fine materials, such as silica fume, the difference between the bond condition of the upper and lower rebars disappears. What is more, it is possible to achieve a better quality bond for the upper rebars as a result of casting from the bottom of a mould. Based on a comparison of the changes of the bond condition in the specimens studied in this project with the guidelines given in the current regulations [1-3], one may conclude that it is purposeful to define new criteria for the assessment of the bond condition for highperformance self-compacting concretes by taking into consideration the direction of concrete mix casting.

\subsection{Effect of casting direction}

An analysis of the courses of the bond functions, the values of the bond stress obtained both along and across the horizontal specimen, show a positive influence of casting from the bottom of a mould on the rebar-concrete 
bond phenomenon. As the main cause of the positive impact of bottom-up casting, one may point towards more effective self-venting and self-compacting of the mixture. This leads to a decrease of the number of air cells in the rebar-concrete contact layer without limiting the settlement of the mix under the upper rebars. Casting a concrete mixture from the bottom causes that the first layer is lifted up and spreads along an element. The final top layer of concrete has thus enough time to vent and compact itself. The concrete cover formed in this way under the rebars in the upper part of the specimen is characterized by better quality than in the case of traditional casting from the top of a mould. A lack of a clear influence of the casting direction on the bond behaviour of the rebars situated in the lower part of the element additionally supports this hypothesis.

\section{Conclusions}

The main problem considered in this work is the effect of the direction of HPSCC mix casting on its bond to rebars. The following conclusions can be drawn from the results of the research presented earlier in this article:

- Bond characteristics: bond stiffness, ultimate and critical bond strength, effect of the rebar distance from the casting point show an improvement for the rebars situated in the upper part of an element in the case of casting the mix from the bottom of a mould. This casting variant leads to an effective removal of air cells from the rebar-concrete contact layer and limits the mixture settlement under the upper rebars.

- In the case of casting from the top, there is a reduction of the ultimate bond stress with the distance from the concrete casting point. In the author's experiment, the maximum bond reduction value between the successive top and bottom rebars across the length of the specimen was $12.5 \%$. In the case of casting the concrete mix from the bottom of a mould, there were either no changes or there was an increase of the ultimate bond stress with the distance from the casting point. The value of the maximum bond increase between the successive top and bottom rebars across the length of the specimen was $13 \%$.

- The quality of the bond condition does not change significantly with the distance of samples from the concrete mixture casting point. Concreting from the top of a mould leads to a reduction of the bond between the top and bottom specimens across the specimens. In the experiment discussed in this work, the top-bottom bond stress ratio was in the range 0.90-0.97. Concreting from the bottom of the mould leads typically to a higher bond stress in the upper rebars comparing to the lower rebars. In the tests performed by the authors, the top-bottom bond stress ratio was in the range from 0.98 to 1.18 . Concreting from the bottom of a mould eliminates the top-bar effect.

- It is advisable to establish new criteria for the assessment of the bond condition in high performance self-compacting concretes taking into account the direction of concrete mixture casting.

\section{References}

1. ACI 318. Building Code Requirements for Structural Concrete. American Concrete Institute (2011)

2. EN 1992. Design of concrete structures, Part 1-1: General Rules, and Rules for Buildings, European Committee for Standardization (2008)

3. FIB Bulletin No. 65. Model Code 2010. Final draft Volume 1 (2012)

4. FIB, Bulletin No. 10. Bond of reinforcement in concrete, state of the art Report prepared by Task Group Bond Models, former CEB, Task Group 5.2.CH-1015, Lausanne, August (2000)

5. P. Dybel, K. Furtak, The effect of ribbed reinforcing bars location on their bond with high-performance concrete, Archives of Civil and Mechanical Engineering, 15 (4), 1070-1077 (2015)

6. J.J. Luke, B.S. Hamad, J.O. Jirsa, J.E. Breen, The Influence of Casting Position on Development and Splice Length of Reinforcing Bars. Research Report No. 242-1, Center for Transportation Research, Bureau of Engineering Research, University of Texas at Austin (1981)

7. P.R. Jaunty, D. Mitchell, M.S. Mirza, Investigation of top bar effects in beams, ACI Materials Journal 85 (3), 251-257 (1988)

8. T. Castel, K. Vidal, Viriyametanont, R. Francois, Effect of reinforcing bar orientation and location on bond with self-consolidating concrete, ACI Structural Journal 103 (4), 559-567 (2006)

9. H.T. Le, M. Müller, K. Siewert, H.M. Ludwig, The mix design for self-compacting high performance concrete containing various mineral admixtures, Materials and Design, 72, 51-62 (2015)

10. M. Gesoğlu, E. Guneyisi, E. Ozbay, Properties of self-compacting concretes made with binary, ternary, and quaternary cementitious blends of fly ash, blastfurnace slag, and silica fume, Construction and Building Materials 23, 1847-1854 (2009)

11. M. Jalal, A. Pouladkhan, O.F. Harandi, D. Jafari:Comparative study on effects of Class F fly ash, nano silica and silica fume on properties of high performance self compacting concrete, Construction and Building Materials 94,90-104 (2015)

12. M. Valcuende, C. Parra, Bond behaviour of reinforcement in self-compacting concretes, Construction and Building Materials 23, 162-170 (2009)

13. P. Desnerck, G. De Schutter, L. Taerwe, Bond behaviour of reinforcing bars in selfcompacting concrete: experimental determination by using beam tests, Materials and Structures 43, 53-62 (2010)

14. K.H. Khayat, K. Manai, A. Trudel, In situ mechanical properties of wall elements cast using 
self-consolidating concrete, ACI Material Journal 94 (6), 491-500 (1997)

15. K.G. Trezos, I.P. Sfikas, K. Orfanopoulos, Bond of self- compacting concrete incorporating silica fume: top-bar effect, effects of rebar distance from casting point and of rebar-to-concrete relative displacements during setting, Construction and Building Materials 73, 378-390 (2014)

16. I.P. Sfikas, K.G Trezos, Effect of composition variations on bond properties of selfcompacting concrete specimens, Construction and Building Materials 41, 252-262 (2013)

17. E.M. Golafshani, A. Rahai, M.H. Sebt, Bond behavior of steel and GFRP bars in self-compacting concrete, Construction and Building Materials 61, 230-240 (2014)

18. L.N. Thrane, C. Pade, C. Idzerda, M. Kaasgaard, Effect of rheology of SCC on bond strength of ribbed reinforcement bars. In design, production and placement of self-consolidating concrete. In: Khayat KH, Feys D, editors. Proceedings of SCC2010 RILEM conference, Montreal, Canada, September 26-29, RILEM book series 1. New York: Springer (2010) 367-78

19. K.M.A. Hossain, M. Lachemi Bond behavior of self-consolidating concrete with mineral and chemical admixtures. ASCE Journal of Materials in Civil Engineering 20 (9), 608-616 (2008)

20. A. Foroughi, S. Dilmaghani S, H. Famili, Bond strength of reinforcement steel in self-compacting concrete, International Journal of Civil Engineering 6 (1), 24-33 (2008)

21. Z. Huang, B. Engström, J. Magnusson, Experimental investigation of the bond and anchorage behaviour of deformed bars in high strength concrete. In: Report 94:4. Chalmers: Chalmers University of Technology (1996).

22. C.O. Orangun, J.O. Jirsa, J.E. Breen, A reevaluation of test data on development length and splices, ACI Journal 74 (3), 114-122 (1977)

23. EN 10080, Steel for the Reinforcement of Concrete, (2007)

24. RILEM TC, RILEM Recommendations for the Testing and Use of Constructions Materials, RC 6 Bond Test for Reinforcement Steel. Pull-Out Test, 1983. E\&FN SPON (1994) 